\title{
FAKTOR-FAKTOR YANG BERHUBUNGAN DENGAN PEMANFAATAN POS KESEHATAN DESA DI WILAYAH KERJA PUSKESMAS AMPANA TIMUR
}

\author{
Factors Related To The Utilization Of Village Health Post In The Area \\ (POSKESDES) Of Community Health Centre Ampana Timur
}

\author{
Eka Megawati1, Bagoes Widjanarko², Priyadi Nugraha ${ }^{3}$ \\ 1,2,3 Bagian Promosi Kesehatan Universitas Diponegoro \\ Email: ekamegawati@gmail.com
}

\begin{abstract}
ABSTRAK
Wilayah kerja Puskesmas Ampana Timur terdapat 10 wilayah kerja, di puskesmas ampana timur memiliki gedung poskesdes 10 unit. Namun bahwa lebih dari setengah jumlah Kepala keluarga yang tidak memanfaatkan Poskesdes dan setiap bulannya jumlah kunjungan tidak mengalami peningkatan. Tujuan penelitian untuk mengetahui faktor-faktor yang berhubungan dengan pemanfaatan Poskesdes diwilayah kerja Puskesmas Ampana Timur. Jenis penelitian yang digunakan adalah kuantitatif dengan rancangan cross sectional. Populasi pada penelitian ini adalah Ibu rumah tangga di Wilayah Kerja Pusksmas Ampana Timur. Jumlah Sampel pada Penelitian ini adalah 81 responden. Analisis data menggunakan analisis univariat,bivariat dan multivariat. Hasil analisis bivariat terdapat 4 variabel yang berhubungan yaitu pengetahuan poskesdes $(p=0,000)$, persepsi terhadap Poskesdes $(p=0,031)$, dukungan suami terhadap pemanfaatan Poskesdes $(\mathrm{p}=0,000)$ dan dukungan Sarana Prasarana terhadap pemanfaatan poskesdes $(\mathrm{p}=0,028)$ dan terdapat 3 variabel yang tidak berhubungan dengan Pemanfaatan Poskesdes yaitu sikap ( $\mathrm{p}=0,280)$, Dukungan Tokoh Agama $(\mathrm{p}=0,91)$ dan Dukungan Petugas Kesehatan $(\mathrm{p}=0,434)$. Hasil analisis multivariat terdapat faktor yang berpengaruh yaitu faktor dukungan suami $(\mathrm{p}=$ 0,001; OR=6,235; 95\% CI ; 2,085 - 18,651). Kepada masyarakat agar berpartisipasi memanfaatkan Poskesdes sebagai fasilitas kesehatan desa dan diharapkan suami memberikan dukungan berupa motivasi kepada anggota masyarakat.
\end{abstract}

Kata Kunci $\quad$ : Perilaku, Keluarga, Pos kesehatan desa

\section{ABSTRACT}

Area of work of Community Health Centre Ampana Timur has 10 units of village health post (Poskesdes). However, there are still a number of families who do not utilize Poskesdes and every month the amount of visits has not increased and it is also proven from the health issues faced. The purpose of research to know the factors related to the utilization of Poskesdes. This study used quantitative method with crosssectional design. The population of the study are housewives from the area of work of Community Health Centre (Puskesmas) Ampana Timur. The number of samples in this study were 81 respondent. Data analysis used were univariate, bivariate, multivariate data analysis. There are 4 variables in the result of bivariate analysis related to the Poskesdes knowledge $(p=0,000)$, perception toward Poskesdes $(p=0,031)$, husband's support toward the utilization of Poskesdes $(p=0,000)$ and the support of facilities and infrastructure toward the utilization of Poskesdes $(p=0,028)$ and there are 3 variables which are not related to the utilization of Poskesdes, namelyattitude $(p=0,280)$, support of religious leaders $(p=0,91)$ and support of health workers $(p=0,434)$. There are factors that affect the result of multivariate analysis, that is husband's sup$\operatorname{port}(p=0,001 ;$ OR=6,235; 95\% CI ; 2,085 - 18,651). To the people are expected to participate by utilize the Poskesdes as village health facility, and husband are expected to provide support in the form of motivation to the members of the society.

Keywords : Family, Utilization, Village Health Post

\author{
Sekretariat \\ Editorial: Kampus FKM UNISMUH PALU - Palu 94118, \\ Sulawesi Tengah, Indonesia \\ Telp/HP: +6281245936241, Fax (0451) 425627 \\ E-mail: jurnal.mppki@gmail.com \\ OJS: http://jurnal.unismuhpalu.ac.id/index.php/PJKM
}

\author{
Article History: \\ $\Rightarrow \quad$ Received 26 April 2018 \\ $\Rightarrow \quad$ Revised 10 Mei 2018 \\ $\Rightarrow \quad$ Accepted 24 Mei 2018 \\ $\Rightarrow \quad$ Available online 25 Juni 2018
}




\section{PENDAHULUAN}

Berdasarkan Sistem Kesehatan Nasional (SKN) salah satu tujuan SKN yaitu terselenggaranya upaya pelayanan, advokasi dan pengawasan sosial oleh perorangan, kelompok dan masyarakat di bidang Kesehatan secara berhasil dan berdaya guna, untuk menjamin terselenggaranya pembangunan kesehatan agar meningkatnya derajat kesehatan masyrakat. Namun saat ini, masyarakat masih diposisikan sebagai subjek dan masih ada upaya kesehatan yang belum menyentuh masyarakat pinggiran dan masyarakat desa. Untuk itu perlu adanya pembentukan Upaya Kesehatan Bersumberdaya Masyarakat (UKBM) (Depkes, 2006).

UKBM dibentuk berdasarkan kebutuhan masyarakat, dikelola oleh dari, untuk dan bersama masyarakat, dengan bimbingan dari petugas Puskesmas, lintas sektor dan lembaga terkait lainnya. Perkembangan pemberdayaan masyarakat saat ini telah banyak UKBM yang berkembang antara lain: Pos Pelayanan Terpadu (Posyandu), Pondok Bersalin Desa (Polindes). Agar lebih menstabilkan penyelenggaraan UKBM yang berada di desa, maka dikembangkan suatu UKBM yang berfungsi untuk mengkoordinasi seluruh UKBM yang ada yaitu Pos Kesehatan Desa (Poskesdes). Pos Kesehatan Desa dibentuk di desa dalam rangka mendekatkan atau menyediakan pelayanan kesehatan dasar masyarakat desa yang bertujuan agar terwujudnya masyarakat sehat yang siaga terhadap permasalahan kesehatan di desa. Poskesdes dikelola oleh seorang bidan dan minimal satu orang kader (Depkes, 2006).

Berdasarkan profil sulawesi tengah jumlah poskesdes yang menjadi binaan Puskesmas di Sulawesi tengah sebanyak 909 unit, jika ditinjau dari desa/kelurahan yang ada di sulawesi tengah 1.803 desa/ kelurahan maka masih ada 894 desa/ kelurahan yang tidak mempunyai Poskesdes. memberikan gambaran persentase rumah tangga yang memanfaatkan pelayanan posyandu atau poskesdes di Provinsi Sulawesi Tengah selama tiga bulan terakhir. di Provinsi Sulawesi Tengah sebanyak $33,0 \%$ rumah tangga memanfaatkan pelayanan di posyandu atau poskesdes. Sebanyak 60,4\% rumah tangga menyatakan tidak membutuhkan pelayanan di posyandu atau poskesdes (DINKES SULTENG, 2014).

Berdasarkan profil 2014 bahwa wilayah kerja puskesmas ampana timur terdapat 10 wilayah kerja, di puskesmas ampana timur memiliki gedung poskesdes 10 unit. Di wilayah Ampana Timur sebagian besar masyarakat belum memanfaatkan Poskesdes yang dapat di buktikan dengan berbagai kasus kesehatan. Kasus penyakit menular di wilayah Ampana Timur pada tahun 2015 adalah malaria klinis 1.772 orang Positif dengan pemeriksaan DDR 15 orang, TB Paru BTA (+) dan TB Paru ( $\mathrm{RO}+$ ) ditemukan 6 kasus dan TB Paru klinis ( Suspek ) 88 kasus, Penderita Kusta MB sebanyak 9 orang, untuk penyakit demam berdarah tidak ditemukan kasus. Pada tahun 2017 terdapat bayi gizi buruk sebanyak 5 bayi dari 349 kelahiran. Data yang didapatkan dari hasil survey awal bahwa data kunjungan di puskesmas setiap hari mencapai 230 kunjungan dari 529 rumah tangga di bandingkan dengan kunjungan di poskesdes setiap hari hanya ada 2 sampai 3 orang berkunjung atau memanfaatkan pelayanan kesehatan di poskesdes (L'information, 2015).

Berdasarkan uraian diatas maka penulis tertarik untuk melakukan Penelitian tentang "Faktor-faktor yang mempengaruhi Pemanfaatan Poskesehatan Desa”. Penelitian ini bertujuan untuk mengetahui Perilaku Keluarga Dalam Pemanfaatan Pelayanan

\section{METODE PENELITIAN}

Penelitian ini dilaksanakan di wilayah kerja puskesmas Ampana Timur Provinsi Sulawesi Tengah. Jenis penelitian yaitu penelitian kuantitatif dengan rancangan cross sectional yang mengetahui hubungan variabel pengetahuan, sikap, Persepsi, Sarana Prasana, Dukungan Suami, Dukungan Tokoh agama dan Dukungan Petugas Kesehatan dengan variabel dependen yaitu Pemanfaatan Poskesehatan Desa. Populasi pada penelitian ini adalah 529. Populasi didapatkan sebanyak 81 dengan subyek penelitian adalah Ibu Rumah Tangga. Cara pengambilan sampel yaitu menggunakan cara Simple Random Sampling. Pengumpulan data pada penelitian ini yaitu data primer melalui wawancara responden dengan acuan kuesioner yang telah dibuat dan data sekunder didapatkan melalui data dari Poskesdes. pengolahan data dilakukan 
melalui SPSS dengan analisis data Univariat, Bivariat dan Multivariat

\section{HASIL}

\section{Pemanfaatan Pos Kesehatan Desa (Poskesdes)}

Distribusi responden berdasarkan Pemanfaatan Poskesdes menunjukkan bahwa dari 81 responden diperoleh 42 responden (51,9\%) tidak memanfaatkan Pos Kesehatan Desa dan 39 $(48,1 \%)$ responden yang memanfaatkan Pos Kesehatan Desa (Lihat lampiran, tabel 1).

\section{Pengetahuan}

Distribusi responden berdasarkan pengetahuan tentang Poskesdes menunjukkan Bahwa dari 81 responden diperoleh pengetahuan yang kurang baik sebanyak 36 responden $(44,4 \%)$ dan yang memiliki pengetahuan baik sebanyak 45 responden (55,6\%) (Lihat lampiran, tabel 2).

\section{Sikap}

Distribusi responden berdasarkan sikap menunjukkan bahwa dari 81 responden diperoleh sikap yang kurang baik terhadap pemanfaatan poskesdes sebanyak 33 responden $(40,7 \%)$ dan yang memiliki sikap baik sebanyak 48 responden (59,3\%) (Lihat lampiran, tabel 3).

\section{Persepsi}

Distribusi responden berdasarkan persepsi menunjukkan bahwa 81 responden diperoleh persepsi yang kurang baik terhadap pemanfaatan poskesdes sebanyak 36 responden $(44,4 \%)$ dan yang memiliki persepsi baik sebanyak 48 responden $(55,6 \%)$ (Lihat lampiran, tabel 4).

\section{Sarana Prasarana}

Distribusi responden berdasarkan sarana prasarana menunjukkan bahwa 81 responden diperoleh pendapat responden tentang sarana prasarana di poskesdes yaitu responden yang brpndapat sarana prasarana di poskesdes kurang lengkap sebanyak 34 responden $(42,0 \%)$ dan responden yang berpendapat bahwa sarana prasarana lengkap sebanyak 47 responden $(58,0 \%)$ (Lihat lampiran, tabel 5).

\section{Dukungan Suami}

Distribusi responden berdasarkan dukungan suami menunjukkan bahwa dari 81 responden diperoleh responden yang tidak mendapatkan dukungan suami sebanyak 35 responden $(43,2 \%)$ dan responden yang mendapatkan dukungan suami dalam pemanfaatan posksdes sebanyak 46 responden $(56,8 \%)$ (Lihat lampiran, tabel 6).

\section{Dukungan Tokoh Agama}

Distribusi responden berdasarkan Dukungan Tokoh Agama menunjukkan bahwa dari 81 responden diperoleh 38 responden $(46,9 \%)$ berpendapat bahwa tokoh agama kurang mendukung terhadap pemanfaatan pelayanan kesehatan pada poskesdes dan 43 $(53,1 \%)$ responden yang berpendapat bahwa tokoh agama mendukung atau terlibat dalam memberikan informasi manfaat poskesdes (Lihat lampiran, tabel 7).

\section{Petugas kesehatan}

Distribusi responden berdasarkan dukungan petugas kesehatan menunjukkan81 responden diperoleh 40 responden $(49,4 \%)$ berpendapat bahwa petugas kesehatan tidak memberikan motivasi atau informasi tentang pemanfaatan poskesdes sedangkan $41(50,6 \%)$ responden yang berpendapat bahwa petugas kesehatan memberikan informasi tentang manfaat poskesdes (Lihat lampiran, tabel 8).

\section{Hubungan Pengetahuan dengan Pemanfaa- tan Pos Kesehatan Desa}

Hubungan pengetahuan dengan pemanfaatan Pos Kesehatan desa didapatkan dari 36 responden yang memiliki pengetahuan kurang baik terdapat 27 responden $(75,0 \%)$ yang tidak memanfaatkan Poskesdes dan 9 responden $(25,0 \%)$ responden yang memanfaatkan Poskesdes sedangkan dari 45 responden yang memiliki pengetahuan baik terdapat 15 responden $(33,3 \%)$ responden yang tidak memanfaatkan poskesdes dan 30 responden $(66,7 \%)$ yang memanfaatkan posksdes .

Uji statistik Chi Square antara variabel pengetahuan dengan pemanfaatan poskesdes didapatkan $\mathrm{p}$ value $=0,000(\mathrm{p}<0,05)$. Sehingga Ha diterima dan Ho ditolak. Berarti secara statistik ada hubungan antara pengtahuan dengan pemanfaatan Poskesdes di wilayah kerja Puskesmas Ampana Timur.

\section{Hubungan Sikap dengan Pemanfaatan Pos Kesehatan Desa}

Hubungan sikap dengan Pemanfaatan Pos Kesehatan Desa didapatkan dari 33 responden yang memiliki sikap kurang baik terdapat 20 responden $(60,6 \%)$ yang tidak memanfaatkan Poskesdes dan 13 responden $(39,4 \%)$ responden yang memanfaatkan Poskesdes sedangkan dari 48 responden yang memiliki sikap baik terdapat 22 responden $(45,8 \%)$ responden yang tidak memanfaatkan poskesdes dan 26 responden $(54,2 \%)$ yang memanfaatkan posksdes.

Uji statistik Chi Square antara variabel pengetahuan dengan pemanfaatan poskesdes 
didapatkan $p$ value $=0,280(p>0,05)$. Sehingga Ha ditolak dan Ho diterima. Berarti secara statistik tidak ada hubungan antara sikap dengan pemanfaatan Poskesdes di wilayah kerja Puskesmas Ampana Timur.

\section{Hubungan Persepsi dengan Pemanfaatan Pos Kesehatan Desa}

Hubungan persepsi dengan pemanfaatan Pos Kesehatan Desa didapatkan dari 36 responden yang memiliki persepsi kurang baik terdapat 24 responden $(66,7 \%)$ yang tidak memanfaatkan Poskesdes dan 12 responden $(33,3 \%)$ responden yang memanfaatkan Poskesdes sedangkan dari 45 responden yang memiliki persepsi baik terdapat 18 responden $(40,0 \%)$ responden yang tidak memanfaatkan poskesdes dan 27 responden $(60,0 \%)$ yang memanfaatkan posksdes.

Uji statistik Chi Square antara variabel persepsi dengan pemanfaatan poskesdes didapatkan $p$ value $=0,031(p<0,05)$. Sehingga Ha diterima dan Ho ditolak. Berarti secara statistik ada hubungan antara perspsi dengan pemanfaatan Poskesdes di wilayah kerja Puskesmas Ampana Timur.

\section{Hubungan Sarana Prasarana dengan Pem- anfaatan Pos Kesehatan Desa}

Hubungan sarana prasarana dengan pemanfaatan Pos kesehatan Desa didapatkan dari 34 responden yang berpendapat bahwa sarana prasarana Posksdes kurang lengkap terdapat 23 responden $(67,6 \%)$ yang tidak memanfaatkan Poskesdes dan 11 responden $(32,4 \%)$ responden yang memanfaatkan Poskesdes sedangkan dari 47 responden yang berpendapat bahwa sarana prasarana di Poskesdes lengkap terdapat 19 responden $(40,4 \%)$ responden yang tidak memanfaatkan poskesdes dan 28 responden $(59,6 \%)$ yang memanfaatkan posksdes.

Uji statistik Chi Square antara variabel sarana prasarana dengan pemanfaatan poskesdes didapatkan $p$ value $=0,028(p>0,05)$. Sehingga $\mathrm{Ha}$ ditolak dan Ho diterima. Berarti secara statistik tidak ada hubungan antara perspsi dengan pemanfaatan Poskesdes di wilayah kerja Puskesmas Ampana Timur.

\section{Hubungan Dukungan Suami dengan Pem- anfaatan Pos Kesehatan Desa}

Hubungan dukungan Suami dengan pemanfaatan Pos kesehatan desa didapatkan bahwa dari 35 responden yang tidak didukung oleh suami terdapat 28 responden $(80,8 \%)$ yang tidak memanfaatkan Poskesdes dan 7 responden $(20,0 \%)$ responden yang memanfaatkan Poskesdes sedangkan dari 46 responden yang didukung oleh suami terdapat 14 responden $(30,4 \%)$ responden yang tidak memanfaatkan poskesdes dan 32 responden $(69,6 \%)$ yang memanfaatkan posksdes.

Uji statistik Chi Square antara variabel dukungan suami dengan pemanfaatan poskesdes didapatkan $p$ value $=0,000(p<0,05)$. Sehingga Ha diterima dan Ho ditolak. Berarti secara statistik ada hubungan antara dukungan suami dengan pemanfaatan Poskesdes di wilayah kerja Puskesmas Ampana Timur.

\section{Hubungan Dukungan Tokoh Agama dengan Pemanfaatan Pos Kesehatan Desa}

Hubungan dukungan Tokoh Agama dengan Pemanfaatan Pos Kesehatan Desa didapatkan dari 38 responden yang tidak mendapatkan dukung oleh tokoh agama terdapat 24 responden $(63,2 \%)$ yang tidak memanfaatkan Poskesdes dan 14 responden $(36,8 \%)$ responden yang memanfaatkan Poskesdes sedangkan dari 43 responden yang mendapatkan dukungan oleh tokoh agama terdapat 18 responden $(41,9 \%)$ responden yang tidak memanfaatkan poskesdes dan 25 responden $(58,1 \%)$ yang memanfaatkan posksdes.

Uji statistik Chi Square antara variabel dukungan tokoh agama dengan pemanfaatan poskesdes didapatkan $p$ value $=0,091(p>0,05)$. Sehingga Ha ditolak dan Ho diterima. Berarti secara statistik tidak ada hubungan antara dukungan tokoh agama dengan pemanfaatan Poskesdes di wilayah kerja Puskesmas Ampana Timur.

\section{Hubungan Dukungan Petugas Kesehatan Dengan Pemanfaatan Pos Kesehatan Desa \\ Berdasarkan analisis bivariat didapatkan} bahwa 40 responden yang tidak mendapatkan dukungan oleh petugas kesehatan terdapat 23 responden $(57,5 \%)$ yang tidak memanfaatkan Poskesdes dan 17 responden (42,5\%) responden yang memanfaatkan Poskesdes sedangkan dari 41 responden yang mendapatkan dukungan oleh petugas kesehatan terdapat 19 responden $(46,3 \%)$ responden yang tidak memanfaatkan poskesdes dan 22 responden $(53,7 \%)$ yang memanfaatkan posksdes.

Uji statistik Chi Square antara variabel dukungan petugas kesehatan dengan pemanfaatan poskesdes didapatkan $p$ value $=0,434(p>0,05)$. Sehingga $\mathrm{Ha}$ ditolak dan Ho diterima. Berarti secara statistik tidak ada hubungan antara dukungan petugas kesehatan dengan pemanfaatan Poskesdes di wilayah kerja Puskesmas Ampana Timur.

Pengaruh antara Variabel Pengetahuan, Sikap, Persepsi, Dukungan Suami, Dukungan tokoh Agama dan Dukungan Petugas Kesehatan terhadap Pemanfaatan Pos Kesehatan desa 
Hasil analisis multivariat dengan regresi logistik menunjukkan bahwa ada 5 variabel yang memiliki nilai signifikansi sangat besar sehingga dilakukan eliminasi bagi variabel yang memiliki nilai signifikansi yang lebih besar atau lebih dari 0,25 . Setelah dilakukan eliminasi dan dilakukan uji ulang maka di dapatkan bahwa variabel dukungan suami terbukti berpengaruh terhadap pemanfaatan Poskesdes. Ada 5 variabel independen yang di uji dalam uji multivariat dan hanya ada 1 variabel independen yang paling berhubungan dengan variabel dependen pemanfaatan Poskesdes.

Variabel dengan Odds Ratio terbesar yaitu variabel dukungan suami dengan $\mathrm{OR}=6,235$ (95\% CI ; 2,085 - 18,651) hal ini berarti responden yang memiliki dukungan dari suami kemungkinan akan memanfaatkan Poskesdes sebagai sarana kesehatan sebesar 6,235 kali lebih besar dibandingkan responden yang tidak mendapat dukungan dari suami.

\section{PEMBAHASAN}

Hasil dari penelitian diperoleh bahwa ada hubungan antara Pengetahuan dengan Pemanfaatan Pos Kesehatan Desa dengan Nilai $p=0.000$, hal ini menunjukkan bahwa ada hubungan antara pengetahuan dengan pemanfaatan Pos Kesehatan desa. Hasil penelitian ini didukung oleh penelitian terdahulu tentang Pengaruh Pengetahuan dan Sikap Ibu Balita serta Peran Bidan Desa Terhadap Pemanfaatan Posyandu dengan nilai $\mathrm{p}=0,000<0,05$. Responden yang memiliki pengetahuan baik sering mendapatkan informasi dari berbagai sumber seperti petugas kesehatan atau informasi sesama teman yang telah memanfaatkan Poskesdes karena meningkatnya pengetahuan seseorang maka seseorang tersebut akan bertindak berdasarkan informasi dan pengalaman yang ia rasakan.

Pada penelitian yang dilakukan didapatkan bahwa tidak ada hubungan antara Sikap dengan Pemanfaatan Posksedes, hal ini berbeda dengan teori L.green dalam Green \& Kreuter (2005) yang menyatakan bahwa sikap merupakan faktor predisposisi yang dapat mempengaruhi perilaku seseorang. Perubahan sikap seseorang kearah yang positif sangat tergantung dari faktor dalam dan luar diri individu tersebut. Untuk menghasilkan sikap yang positif dari seseorang perlu memberikan pengetahuan dan informasi yang jelas tentang pentingnya kesehatan sehingga dapat mengambil kepu- tusan yang tepat dalam pemanfaatan fasilitas Posksdes dengan didukung oleh semua pihak yang terkait.

Hasil dari penelitian tentang hubungan persepsi dengan pemanfaatan Pos Kesehatan desa sejalan dengan penelitian yang dilakukan oleh Rumengan, dkk (2015) didapatkan nilai signifikansi sebesar 0,001 $(\mathrm{p}<0,05)$ yang berarti ada hubungan yang bermakna antara persepsi responden tentang JKN dengan pemanfaatan pelayanan kesehatan di Puskesmas. Dapat disimpulkan bahwa Persepsi responden dapat dipengaruhi oleh berbagai informasi yang mereka dapatkan dan juga pengalaman yang mereka rasakan langsung dari pemanfaatan Posksdes, dari informasi yang didapatkan dari lingkungan sekitar tentang Poskesdes maka responden akan memiliki persepsi tentang informasi yang mereka dapatkan.

Hasil analisis uji chisquare dengan nilai $\mathrm{p}=0.010$, karena nilai $\mathrm{p}<0.05$ dengan demikian maka Ho ditolak atau dapat disimpulkan bahwa ada hubungan sarana prasarana dengan pemanfaatan pelayanan kesehatan di Puskesmas. Menurut L.Green bahwa Sarana prasarana merupakan salah satu faktor yang dianggap mempengaruhi pemanfaatan pelayanan kesehatan karena dapat menerima pelayanan kesehatan yang diinginkan oleh masyarakat. Sehingga untuk berperilaku sehat, masyarakat memerlukan sarana dan prasarana pendukung.

Hubungan antara dukungan Tokoh Agama dengan Pemanfaatan Pos Kesehatan Desa didapatkan nilai $p=0,091$, yang artinya tidak ada hubungan antara dukungan Tokoh Agama dengan Pemanfaatan Pos Kesehatan Desa. Penelitian yang dilakukan oleh peneliti berbeda dengan penelitian oleh Try Umayana \& Hary Cahyati (2015) tentang dukungan Keluarga dan Tokoh Masyarakat terhadap keaktifan Penduduk ke Posbindu penyakit tidak menular menyatakan bahwa nilai $p$ value sebesar $0,001(<0,05)$ yang artinya ada hubungan antara faktor dukungan tokoh masyarakat dengan keaktifan penduduk ke Posbindu. Dukungan sosial semakin dibutuhkan masyarakat jika terjadi masalah kesehatan atau sakit maka peran tokoh agama/tokoh masyarakat sangat dibutuhkan untuk memotivasi masyarakat memanfaatkan Poskesdes agar dapat mengatasi masalah kesehatan yang ada dimasyarakat. Na- 
mun dalam hal ini, walaupun masyarakat sudah mendapatkan dukungan atau motivasi yang baik dari Tokoh Agama akan tetapi masyarakat juga harus memiliki pengetahuan yang baik dan sikap yang positif tentang poskesdes. Semakin baik pengetahuan dan sikap seseorang terhadap Poskesdes dan juga diberikan motivasi dari lingkungan sekitar maka akan terdorong untuk memanfaatkan Poskesdes.

Ditinjau dari hubungan dukungan suami dengan pemanfaatan Pos Kesehatan desa didapatkan nilai $p=0,000$ yang artinya ada hubungan. Pada penelitian ini dukungan suami juga sangat berpengaruh dalam pemanfaatan Pos Kesehatan desa. Nilai p $<0,001$ yang artinya ada hubungan yang kuat antara dukungan keluarga dengan pemanfaatan fasilitas persalinan. Dukungan keluarga mengacu pada dukungan-dukungan sosial yang dipandang oleh anggota keluarga sebagai suatu yang dapat diakses/diadakan untuk keluarga, dalam hal ini suami sangat berperan penting dalam memberikan motivasi kepada anggota keluarga lainnya untuk memanfaatkan pelayanan kesehatan yang telah disediakan di desa, dengan adanya motivasi dari suami maka anggota keluarga lainnya akan terdorong untuk memanfaatkan pelayanan kesehatan.

Ditinjau dari hubungan dukungan petugas kesehatan dengan pemanfaatan Pos Kesehatan desa didapatkan nilai 0,434 (p > $0,05)$ yang artinya tidak ada hubungan, namun berbeda dengan penelitian yang dilakukan oleh Paola Netsy Purba (2011) Hasil uji chi square dengan nilai $p=0,000<0,05$, artinya ada hubungan antara variabel peran bidan desa dengan pemanfaatan posyandu. Dengan adanya informasi yang dilakukan oleh petugas kesehatan maka masyarakat lebih terdorong dan tertarik sehingga lebih cenderung merubah tingkah lakunya. Dalam penelitian yang peneliti lakukan tidak ada hubungan antara dukungan petugas kesehatan dengan pemanfaatan poskesdes walaupun sebagian besar responden menyatakan bahwa petugas kesehatan memberikan informasi namun tidak semua masyrakat menggunakan fasilitas kesehatan yang ada di desa hal ini disebabkan karna ada faktor dari luar yang dapat mempengaruhi masyarakat misalnya faktor dukungan dari tokoh masyarakat dan juga pengetahuan dari masyarakat itu sendiri.

\section{KESIMPULAN DAN SARAN}

Penelitian ini dapat disimpulkan bahwa ada hubungan antara variabel pengetahuan dengan pemanfaatan poskesdes didapatkan $\mathrm{p}$ value $=0,000(\mathrm{p}<0,05)$, tidak ada hubungan antara sikap dengan pemanfaatan Poskesdes dengan nilai $\mathrm{p}$ value $=$ $0,280$ ( $p>0,05)$, ada hubungan antara persepsi dengan pemanfaatan Poskesdes didapatkan nilai $p$ value $=0,031(p<0,05)$, ada hubungan antara sarana prasarana dengan pemanfaatan Poskesdes dengan nilai $p$ value $=0,028(p>0,05)$, tidak ada hubungan antara variabel dukungan tokoh agama dengan pemanfaatan poskesdes didapatkan $p$ value $=0,091(p>0,05)$, ada hubungan antara variabel dukungan suami dengan pemanfaatan poskesdes didapatkan $\mathrm{p}$ value $=0,000(\mathrm{p}<0,05)$, tidak ada hubungan antara dukungan petugas kesehatan dengan pemanfaatan Poskesdes didapatkan nilai $\mathrm{p}$ value $=0,434(\mathrm{p}>0,05)$. Berdasarkan analisis multivariat bahwa Variabel dukungan suami berpengaruh pada pemanfaatan Pos Kesehatan desa dengan nilai signifikansi 0,000 dan nilai Odds Ratio terbesar yaitu variabel dukungan suami dengan $\mathrm{OR}=6,235$ $(95 \% \mathrm{CI} ; 2,085$ - 18,651) hal ini berarti responden yang memiliki dukungan dari suami kemungkinan akan memanfaatkan Poskesdes sebagai sarana kesehatan sebesar 6,235 kali lebih besar dibandingkan responden yang tidak mendapat dukungan dari suami.

Penelitian ini menyarankan agar membuat program suami siaga dan juga pihak Poskesdes melakukan pendekatan dan kerja sama dengan tokoh masyarakat dalam peningkatan pemanfaatan Poskesdes.

\section{DAFTAR PUSTAKA}

Depkes. (2006). Pengembangan dan Penyelengaraan Pos Kesehatan Desa.

DINKES SULTENG. (2014). PROFIL KESEHATAN PROVINSI SULAWESI TENGAH TAHUN 2011. Igarss 2014, (1), 1-5. https://doi.org/10.1007/ s13398-014-0173-7.2

Green, L. W., \& Kreuter, M. W. (2005). Health program planning: An educational and ecological approach. McGraw-Hill Companies.

Magan, H. (2013). Faktor Yang Berhubungan Dengan Pemanfaatan Pelayanan Kesehatan Unit Rawat Jalan Di Wilayah 
Kerja Puskesmas. Jurnal Universitas Hasanuddin Bagian Administrasi Kebijakan Kesehatan FKM. Retrieved from http://repository.unhas.ac.id/ bitstream/handle/123456789/8327/ jurnal.pdf;sequence $=1$

Nara, A. (2014). Hubungan pengetahuan, sikap, akses pelayanan kesehatan, jumlah sumber informasi dan dukungan keluarga dengan pemnfaatan fasilitas persalinan yang memadai oleh ibu bersalin di Puskesmas Kawangu Kabupaten Sumba Timur.

Purba, Paola Nesty. "Pengaruh Pengetahuan Ibu dan Sikap Balita Serta Peran Bidan terhadap Pemanfaatan Posyandu Di Wilayah Kerja Puskesmas Bosar Maligas." Tesis, 2011.

Puskesmas Ampana Timur. Ampana: Profil Puskesmas; 2015

Rumengan, D. S. S., Umboh, J. M. L., \& Kandou, G. D. (2015). Faktor-Faktor yang Berhubungan dengan Pemanfaatan Pelayanan Kesehatan Pada Peserta BPJS Kesehatan di Puskesmas Paniki Bawah Kecamatan Mapanget Kota Manado. Jikmu, 5(1), 88-100.

Try Umayana, H., \& Hary Cahyati, W. (2015). DUKUNGAN KELUARGA DAN TOKOH MASYARAKAT TERHADAP KEAKTIFAN PENDUDUK KE POSBINDU PENYAKIT TIDAK MENULAR Info Artikel. Kemas, 11(1), 96-101. https:// doi.org/10.15294/ 
LAMPIRAN

Tabel 1. Distribusi Responden berdasarkan Pemanfaatan Pos Kesehatan Desa

\begin{tabular}{lcc}
\hline \multicolumn{1}{c}{ Pemanfaatan Posksdes } & n & (\%) \\
\hline Tidak memanfaatkan & 42 & 51,9 \\
Memanfaatkan & 39 & 48,1 \\
Total & 81 & 100,0
\end{tabular}

Sumber : Data Primer 2017

Tabel 2. Distribusi Responden Berdasarkan Pengetahuan

\begin{tabular}{lcc}
\hline \multicolumn{1}{c}{ Pengetahuan } & n & (\%) \\
\hline Kurang Baik & 36 & 44,4 \\
Baik & 45 & 55,6 \\
Total & 81 & 100,0 \\
\hline
\end{tabular}

Sumber: Data Primer 2017

Tabel 3. Distribusi Responden Berdasarkan Sikap

\begin{tabular}{lcc}
\hline \multicolumn{1}{c}{ Sikap } & n & (\%) \\
& & 40,7 \\
Kurang Baik & 33 & 59,3 \\
Baik & 48 & 100,0 \\
\hline
\end{tabular}

Sumber: Data Primer 2017

Tabel 4. Distribusi Responden Berdasarkan Persepsi

\begin{tabular}{lcc}
\hline \multicolumn{1}{c}{ Persepsi } & n & (\%) \\
& & \\
\hline Kurang Baik & 36 & 44,4 \\
Baik & 45 & 55,6 \\
Total & 81 & 100,0 \\
\end{tabular}

Sumber: Data Primer 2017 
Tabel 5. Distribusi Responden Berdasarkan Sarana Prasarana

\begin{tabular}{lcc}
\hline \multicolumn{1}{c}{ Sarana prasarana } & n & (\%) \\
\hline Kurang lengkap & 34 & 42,0 \\
lengkap & 47 & 58,0 \\
Total & 81 & 100,0 \\
\hline
\end{tabular}

Sumber : Data Primer 2017

Tabel 6. Distribusi Responden Berdasarkan Dukungan Suami

\begin{tabular}{lcc}
\hline \multicolumn{1}{c}{ Dukungan suami } & n & (\%) \\
\hline Tidak mendukung & 35 & 43,2 \\
mendukung & 46 & 56,8 \\
Total & 81 & 100,0 \\
\hline
\end{tabular}

Sumber : Data Primer 2017

Tabel 7. Distribusi Responden Berdasarkan Dukungan Tokoh Agama

\begin{tabular}{lcc}
\hline \multicolumn{1}{c}{ Dukungan tokoh agama } & n & (\%) \\
\hline Tidak mendukung & 38 & 46,9 \\
mendukung & 43 & 53,1 \\
Total & 81 & 100,0
\end{tabular}

Sumber : Data Primer 2017

Tabel 8. Distribusi Responden Berdasarkan Dukungan Petugas Kesehatan

\begin{tabular}{lcc}
\hline \multicolumn{1}{c}{ Dukungan petugas kesehatan } & $\mathrm{n}$ & (\%) \\
\hline Tidak mendukung & 40 & 49,4 \\
mendukung & 41 & 50,6 \\
Total & 81 & 100,0 \\
\hline
\end{tabular}

Sumber : Data Primer 2017 